\title{
Backing into the future: pharmacological approaches to the management of resistant depression
}

\author{
P. J. Cowen* \\ University Department of Psychiatry, Warneford Hospital, Oxford OX3 7JX, UK
}

\begin{abstract}
Pragmatic studies indicate that a substantial number of depressed patients do not remit with current first-line antidepressant treatments and after two failed treatment steps the chance of remission with subsequent therapies is around $15 \%$. This paper focuses on current evidence for pharmacological treatments in resistant depression as well as possible future developments. For patients who have failed to respond to two antidepressant trials, augmentation with atypical antipsychotic drugs, specifically quetiapine and aripiprazole, has the best evidence for efficacy, though older treatments such as lithium and triiodothyronine still have utility. The striking antidepressant effect of ketamine in resistant depression has stimulated research into glutamatergic compounds; however, capturing the efficacy of ketamine with drugs suitable for continuous use has proved challenging. Growing knowledge of the pathophysiological role of inflammation in depression offers great opportunities for future treatment in terms of repurposing anti-inflammatory agents from general medicine and pre-treatment stratification of those depressed patients in whom such interventions are likely to be beneficial. Finally an older drug, the dopamine receptor agonist pramipexole, if used carefully may well improve the prospects of depressed patients who are refractory to current approaches.
\end{abstract}

Received 28 December 2016; Revised 14 February 2017; Accepted 28 February 2017; First published online 25 August 2017

Key words: resistant depression, antidepressant treatment, augmentation, inflammation, ketamine, pramipexole.

\section{Introduction}

Depression, unresponsive to psychological and pharmacological treatment is a common problem in both primary care and psychiatric practice. Progress in this area in recent years has been modest at best, in part because of the withdrawal of much of the pharmaceutical industry from the development of new psychotropic drugs. In these circumstances, pharmacological innovation has had to rely on repurposing available treatments and using what we have as effectively as possible. The latter is made difficult by the focus of UK psychiatric services on patients with psychosis and issues of risk. Many community assessments of persistently depressed people result in the patient simply being discharged back to their GP without continuing support from specialist services. This is presumably because depressed patients are regarded by psychiatric teams as being less disabled and at risk than those with psychosis or severe personality disorder. However, as Lewis has pointed out: '... many people with chronic depression live in extreme isolation, have never worked, cannot travel on their own, and have lives as impoverished as people with chronic schizophrenia' (Lewis, 2016). Of course,

\footnotetext{
* Address for correspondence: P. J. Cowen, University Department of Psychiatry, Warneford Hospital, Oxford OX3 7JX, UK.

(Email: phil.cowen@psych.ox.ac.uk)
}

inadequate treatment of depression is not simply a UK issue, but is clearly a worldwide problem, probably stemming from a combination of lack of service provision together with the modest efficacy of psychological and pharmacological treatments (Paykel, 2006; Pratt \& Brody, 2014).

A recent randomised study in the UK compared treatment as usual (TAU) in a community mental health team $v$. care in a specialist depression service in patients who had experienced persistent depression despite at least 6 months care in secondary services. The findings showed disappointingly little added benefit of the specialist service, even given the availability in the latter of long-term specialist cognitive behaviour therapy, a treatment currently in short supply in UK psychiatric services (Morris et al. 2016). This suggests that we need new approaches that are substantially better than our current therapies to improve outcome in treatment-resistant depression (TRD). Alternatively we need to find ways of identifying which patients might respond to which specific treatment in order to decrease the substantial amount of time spent in empirical trials before an effective approach is identified.

\section{TRD: scope of the problem}

Generally, clinical depression is regarded as having a favourable prognosis and many people recover in 
primary care and the community with straightforward psychological or pharmacological treatments or indeed without any specific treatment at all. However, full recovery may occur less frequently than generally believed, particularly in patients seeking treatment. For example, of 1800 depressed patients starting antidepressant medication in the community in the USA, only about a third were in remission 3 months later (Simon et al. 2006). Similar findings were found in the STAR*D study, a pragmatic investigation of sequenced antidepressant therapies in 2800 US patients with major depression, where first-line treatment with selective serotonin reuptake inhibitor (SSRI) citalopram over 12 weeks was associated with a remission rate of 37\% (Rush et al. 2006). 'Remission' (low post-treatment symptom score) rather than 'response' (at least 50\% decrease in symptom score) is the goal of current treatment because persisting depressive symptoms are associated with a higher risk of relapse (Cowen \& Anderson, 2015).

Patients in $\operatorname{STAR}^{*} \mathrm{D}$ who did not remit with citalopram were offered a series of subsequent treatment steps including switching to a different antidepressant, as well as an number of antidepressant 'augmentation' strategies where SSRI treatment was supplemented with drugs such as bupropion, lithium or triiodothyronine (T3). There seemed to be few important differences in outcome when the various strategies were compared. The main finding of interest was the sharply decreased chance of remission as the number of failed treatment steps increased. Also, after four treatment steps over about 12 months, a third of patients had still not achieved remission and in those that had, there was a high risk of relapse over the next 12 months (Rush et al. 2006). The patients in $\mathrm{STAR}^{*} \mathrm{D}$ were not chosen for probable treatment resistance; the study therefore shows that even in unselected depressed patients starting first-line treatment, a substantial minority have a poor prognosis.

The definition of resistant depression varies between different studies. In pharmacological trials carried out by industry, the usual definition is failure to respond to two separate adequate courses of antidepressant medication. This is consistent with the finding in STAR*D that after failure to remit to two treatment steps, the chances of remission with a subsequent therapy is only about $15 \%$ (Rush et al. 2006). However, the problem with pharmacological definitions of resistant depression is that they do not incorporate failure to respond to psychotherapy, an important consideration. Additionally, other factors such as the length of the episode and its severity are clinically significant but not captured by such a definition. The recommendation from the National Institute for Care and Health Excellence (NICE) is to prioritise treatment sequencing rather than identifying particular kinds of treatmentresistant patients (NICE, 2009) and it does seem to be the case that sequencing treatments by algorithm produces better outcomes in depression (Bauer et al. 2009). However, eventually it is to be hoped that treatment algorithms can be replaced by strategies that match patients to specific therapies, based on pre-treatment clinical, social and biological markers.

\section{Current pharmacological approaches}

\section{Treatment switching}

If a patient fails to respond to first-line antidepressant medication, the usual advice, endorsed by NICE, is to switch to a second antidepressant (NICE, 2009). Most patients are now treated initially with an SSRI and, rather surprisingly, it seems to make little difference to outcome whether or not they are switched to a second SSRI or a different class of antidepressant, for example mirtazapine or bupropion. The exception to this may be the serotonin and noradrenaline re-uptake inhibitor (SNRI) venlafaxine, which in a meta-analysis of 1500 patients switched from ineffective SSRI treatment, was modestly better than a second SSRI in achieving remission with a number needed to treat (NNT) of about 13 (Papakostas et al. 2008).

Vortioxetine is a more recently developed antidepressant which is a serotonin re-uptake blocker with modulatory effects on several other serotonin receptor subtypes. The latter action is claimed to produce benefits on cognitive performance which are not simply an indirect consequence of alleviation of depressed mood (Mahableshwarkar et al. 2015), though the evidence for this in terms of measurable functional improvements, for example, in work performance in depressed patients is not yet available. However, vortioxetine has been studied in depressed patients failing to respond to first-line SSRI/SNRI treatment where in a 'switch' study, it proved more efficacious than the melatonergic antidepressant, agomelatine (Montgomery et al. 2014).

Some other antidepressant drugs have a clinical reputation for being more effective in severely depressed and treatment-resistant patients. These include the tricyclic antidepressants (TCAs), amitriptyline and clomipramine, which are worth considering in patients with resistant depression if they can be given safely (Cowen \& Anderson, 2015). Similar comments apply to monoamine oxidase inhibitors (MAOIs) (Nolen et al. 1985), though the use of these agents is limited by drug and food interactions and many younger practitioners do not have experience of prescribing them. Another practical difficulty is that most treatment-resistant depressed patients who 
might be considered for MAOI therapy are currently taking serotonergic antidepressants such as SSRIs or venlafaxine and such drugs are contraindicated with MAOIs because of the risk of serotonin toxicity. However, stopping drugs such as venlafaxine over a timeframe, which avoids unpleasant withdrawal symptoms, and then leaving a suitable 'washout' period before the MAOI is introduced, can be a difficult exercise for a depressed and despairing patient to tolerate, particularly at a time when even the most severely depressed patients are managed in the community.

There are also economic barriers to the use of some MAOIs currently, with tranylcypromine and isocarboxazid being subject to staggering price increases in association with generic status and a single manufacturer. This issue, which extends beyond drugs used in psychiatry, has been discussed in the media (http://www.bbc.co.uk/news/health-36449913) and is the subject of an enquiry by the Competition and Markets Authority. In the meantime, if an MAOI is to be used, generic phenelzine is still available at a reasonable cost. In this context it is worth noting that the reversible MAO-A inhibitor, moclobemide, does not seem to be as effective as the older non-selective MAOIs in the treatment of resistant depression (Cowen, 2005).

\section{Combination and augmentation strategies}

Combination and augmentation approaches are typically used when switching antidepressant medications has failed to produce sufficient clinical improvement. In both cases, the existing ineffective or partially effective treatment is continued, and the second agent is added. Conventionally, combination refers to the addition of a second drug thought itself to have antidepressant abilities (for example, mirtazapine), while augmentation consists of adding a drug not thought to be an antidepressant in its own right (for example, lithium).

Antidepressant combinations are frequently used, for example the addition of mirtazapine to ineffective SSRI or SNRI treatment. In the USA, the addition of bupropion to ineffective SSRI treatment is also popular. Neither of these approaches is supported by a strong evidence base; however, a large UK trial of mirtazapine addition to SSRIs should be reporting shortly (http://www.isrctn.com/ISRCTN06653773). In the STAR*D study, the addition of bupropion to SSRI treatment was modestly better than buspirone addition in a number of secondary outcome measures (Trivedi et al. 2006).

A wide variety of agents have been employed to augment ineffective SSRI treatment. The best evidence base is for the use of atypical antipsychotic drugs. In a meta-analysis of randomised trials in 3500 patients that compared the addition of placebo with that of an atypical antipsychotic, significant benefit was found for quetiapine, aripiprazole and risperidone to achieve remission with an NNT of 9. Olanzapine was also effective relative to placebo, but the NNT to achieve remission was greater (19) (Spielmans et al. 2013). Atypical antipsychotics, when used for augmentation of antidepressants, are prescribed in lower doses than those used in the treatment of psychosis, for example 2.5-10 mg of aripiprazole, or 50-300 mg of quetiapine. Despite this, tolerance of atypical antipsychotic addition in depression can be problematic with side effects such as sedation and weight gain with quetiapine and extrapyramidal movement disorders with aripiprazole. Significantly, the number needed to harm (NNH) with antipsychotic drug augmentation, reckoned by dropouts from randomised trials through adverse effects, is only about twice as great as the NNT $(\mathrm{NNH}=17)$ (Nelson \& Papakostas, 2009).

Other agents used in augmentation of ineffective antidepressant treatment include lithium and T3. Meta-analyses continue to demonstrate that lithium addition is effective in producing an antidepressant response but overall, despite the long history of lithium use for this indication, the number of patients studied (under 250) is quite small. In addition, most of the earlier studies investigated lithium combined with TCA treatment and there are less data on the utility of lithium when added to SSRI and SNRI treatments (Nelson et al. 2014). However, the well-established ability of lithium to lower suicidal behaviour in mood disorders (Cipriani et al. 2013) is an important consideration in its use in resistant depression.

Most studies of T3 have also involved addition to TCA treatment and there have been few recent investigations. In the STAR*D study, T3 (25-50 $\mu$ g daily) was numerically superior to lithium in producing remission in patients who had failed to respond to two previous antidepressant treatment steps and T3 was better tolerated. However, remission rates of both treatments were low (23\% v. 16\%) (Nierenberg et al. 2006). Numerous other agents have been trialed as augmentation agents, some of which are listed in Table 1. A number of these, for example, S-adenosyl-methionine, are of particular interest because of their tolerance and safety, and are worth exploring further in larger scale investigations.

In a network meta-analysis of 48 trials involving over 6500 participants, Zhou et al. (2015) assessed the effect of several augmentation strategies in TRD. The agents studied included atypical antipsychotics, lithium and T3 but also methylphenidate, pindolol, lamotrigine and buspirone. The meta-analysis found that 
Table 1. Some antidepressant augmenting agents used in treatment-resistant depression (TRD) ${ }^{\mathrm{a}}$

\begin{tabular}{|c|c|c|}
\hline Augmenting agent & Proposed mechanism & Comment \\
\hline Pindolol & $\begin{array}{l}5-\mathrm{HT}_{1 \mathrm{~A}} \text { receptor } \\
\text { antagonist }\end{array}$ & May speed SSRI onset; ineffective in TRD in larger trials (Pérez et al. 1979) \\
\hline Buspirone & $5-\mathrm{HT}_{1 \mathrm{~A}}$ partial agonist & $\begin{array}{l}\text { Used in STAR*D; no consistent placebo-controlled data suggesting } \\
\text { efficacy in TRD (Trivedi et al. 2006) }\end{array}$ \\
\hline Lamotrigine & Glutamate antagonist & $\begin{array}{l}\text { Effective in bipolar depression; uncertain efficacy in TRD } \\
\text { (Barbee \& Jamhour, 2002) }\end{array}$ \\
\hline S-adenosylmethionine & Methyl donor & Effective in study of SSRI-resistant patients (Papakostas et al. 2010) \\
\hline Folic acid & Methyl donor & Ineffective in a recent large trial (Bedson et al. 2014) \\
\hline L-methylfolate & Methyl donor & Possibly effective in a dose of $15 \mathrm{mg}$ daily (Papakostas et al. 2012) \\
\hline Metyrapone & Blocks cortisol synthesis & Ineffective in a recent large trial (McAllister-Williams et al. 2016) \\
\hline Modafinil & Stimulant & Moderately effective in meta-analysis (Goss et al. 2013) \\
\hline Lisdexamfetamine & Stimulant & Ineffective in phase 3 trials (Papakostas \& Ionescu, 2015) \\
\hline $\begin{array}{l}\text { Eicosapentaenoic acid } \\
\text { (EPA) }\end{array}$ & Anti-inflammatory & Possibly effective in small randomised trials (Nemets et al. 2002) \\
\hline
\end{tabular}

${ }^{\text {a }}$ Adapted from Cowen \& Anderson (2015).

quetiapine, aripiprazole, T3 and lithium were significantly more effective than placebo, with the most robust efficacy estimates for aripiprazole and quetiapine. Controlled studies of atypical antipsychotic augmentation in resistant depression are generally short-term and the appropriate duration of treatment in patients who remit is not well established. In naturalistic studies, the majority of patients apparently stay on combination treatment for several months (Pae et al. 2015).

\section{New approaches}

\section{Ketamine and related agents}

Ketamine is a general 'dissociative' anaesthetic which blocks a subtype of glutamate receptor called the $N$-methyl-D-aspartate (NMDA) receptor. In psychiatric research, ketamine has been employed as a pharmacological model of schizophrenia because, at subanaesthetic doses, it produces transient psychotic symptoms and cognitive impairment. This observation has contributed to the NMDA receptor 'hypofunction' hypothesis of schizophrenia (Olney et al. 1999). More recently, it has been demonstrated that administration of ketamine at sub-anaesthetic doses (usually about $0.5 \mathrm{mg} / \mathrm{kg}$ ) can produce striking amelioration of depressive symptoms in patients with resistant depression. The antidepressant effects of ketamine emerge as its dissociative effects wane, about an hour following intravenous administration. Perhaps more strikingly, in a proportion of patients these antidepressant effects are prolonged, in some cases for up to a week. A number of systematic reviews of the antidepressant effect of ketamine have appeared. For example, Kishimoto et al.
(2016) found in nine randomised controlled trials that relative to placebo (intravenous saline or midazolam) ketamine produced a significant antidepressant response from the end of the infusion lasting up to 7 days post treatment with an NNT of $2-5$. The same report also analysed five placebo-controlled, intravenous trials of non-ketamine NMDA receptor antagonists developed by industry. Here the findings were positive but less striking than those of ketamine, with the drugs proving superior to placebo in terms of response between days 2 and 5 .

Consistent with its effect to alleviate depressed mood rapidly, ketamine has also been reported to diminish concomitant suicidal ideation markedly, an effect of potentially great clinical significance. However, in a review, Wilkinson \& Sanacora (2016) caution that ketamine's alleviation of suicidal thinking, like its effects on depression, are transient, and it is not yet clear that any antisuicidal activity of ketamine is distinct from its antidepressant effect. They suggest further controlled trials, specifically in patients with high pre-treatment levels of suicidal thinking.

The main clinical problem in using ketamine is, of course, the transient nature of response. Thus far it has not been possible to maintain the therapeutic effect of ketamine with readily available glutamatergic agents such as riluzole and memantine (Mathew et al. 2010). New forms of ketamine that can be administered more continuously, orally or intranasally, are being developed and are in clinical trials. Here the issue will be to assess whether the antidepressant effects of ketamine can be sustained without the development of therapeutic tolerance or safety concerns (for example, dependence, psychosis, bladder toxicity). A 
potentially important development, based on animal studies, is the suggestion that the antidepressant effect of ketamine may depend principally on the ability of its active metabolite, hydroxynorketamine, to stimulate another subtype of glutamate receptor, the AMPA ( $\alpha$-amino-3-hydroxy-5-methyl-4-isoxazolepropionic acid) receptor (Zanos et al. 2016), although whether efficacious levels of the metabolite are achieved with the ketamine doses used has been disputed (Collingridge et al. in press). Nevertheless, hydroxynorketamine could be free of many of the safety problems associated with ketamine and studies of its clinical efficacy in depressed patients are therefore a priority.

As noted above, the compelling antidepressant effect of ketamine has led to the development by industry of novel agents acting on the glutamate system, particularly the NMDA receptor. For example, traxoprodil is a selective antagonist at the GluN2B subtype of the NMDA receptor, while lanicemine is a 'low trapping' nonselective antagonist of the NMDA receptor which should theoretically be associated with fewer psychotomimetic effects than ketamine. Both drugs showed promising and rapid antidepressant effects in early studies, but phase 2 trials were disappointing and drug development abandoned. Another approach has been to develop agents acting at the glycine modulatory site of the NMDA receptor such as the partial agonist, GLYX-13 (Rapastinel), which is currently in phase 3 trials in patients with major depression (Papakostas \& Ionescu, 2015).

Nitrous oxide has interesting pharmacological parallels with ketamine in that it is also an anaesthetic with antagonist properties at the NMDA receptor (Jevtović-Todorović et al. 1998). In a double-blind, placebo-controlled crossover study, Nagele et al. (2015) found that nitrous oxide (50\% gas and air) administered for $1 \mathrm{~h}$ produced an antidepressant effect in patients with resistant depression, which lasted for the following $24 \mathrm{~h}$. Like ketamine, nitrous oxide is misused for its euphoriant and psychedelic properties and prolonged use has been associated with acute vitamin $\mathrm{B}_{12}$ depletion with serious adverse neurological and psychiatric consequences (Blanco and Peters, 1983).

Finally, another psychedelic agent, psilocybin, a serotonin receptor agonist, has been examined for its potential in the treatment of resistant depression. The mechanistic notion here is rather different from that of treatment with NMDA receptor antagonists and relates more to the long-term psychological and spiritual impact of the psychedelic experience. Thus, it is suggested that a few treatments with psilocybin can produce enduring benefits in personal adjustment and well-being.

Testing this suggestion in a controlled setting is challenging. Carhart-Harris et al. (2016) carried out an open- label study in 12 patients with resistant depression who received two psilocybin doses administered 1 week apart. The psilocybin was well tolerated and produced a rapid and striking decrease in depressive symptoms which, in half the group, was maintained at 3 months. Clearly the therapeutic use of psilocybin is made difficult by the idiosyncratic nature of the psychological response and the need for intensive support and monitoring during administration of the treatment. In the UK, psilocybin is also a class A substance, making possession without a special Home Office licence illegal. However, the fact that psilocybin might produce therapeutic benefit in psychiatric conditions for which current pharmacological and psychological treatment are of only limited effectiveness, makes further careful study worthwhile. Nevertheless, it is important to remember that psychiatry has a troubled history with dramatic, physical treatments some of which were eventually revealed to be of no specific therapeutic value but certainly harmful - insulin coma treatment is an example.

\section{Pramipexole}

Many of the symptoms of depression, for example anhedonia and loss of motivation, involve brain mechanisms that are regulated by dopamine neurons (Dunlop \& Nemeroff, 2007). Despite this, few antidepressants have direct effects on dopamine neurotransmission with the exception of MAOIs and, to some extent, bupropion. The dopamine agonist, pramipexole, is widely used in the treatment of Parkinson's disease and there have been placebo-controlled trials in depression, with the most positive findings obtained in bipolar depressed patients (Goldberg et al. 2004; Zarate et al. 2004). In patients with resistant unipolar depression, one placebo-controlled study of 60 patients showed equivocal benefit (Cusin et al. 2013) while the combination of escitalopram and pramipexole as a first-line treatment of depression seemed less effective than either drug given alone (Franco-Chaves et al. 2013).

A recent case series reported on 42 outpatients, 24 with major depression, the remainder with bipolar depression. Patients were refractory to current treatments and all had failed at least four treatment steps. Eight had also not responded to ECT treatment. Pramipexole was added in a single dose at night to current therapy starting at $0.25 \mathrm{mg}$ daily, aiming for a dose of $2 \mathrm{mg}$ over about 3 weeks. Patients tolerating the $2 \mathrm{mg}$ daily dose but not responding had further dose increases up to a maximum of $5 \mathrm{mg}$ a day. The average dose of pramipexole given was about $2.5 \mathrm{mg}$ a day. The results of the intervention were striking for patients with this degree of treatment resistance 
in that 20 patients remitted and a further 12 responded. Ten patients were non-responders but in eight, the reason for this was non-tolerance of pramipexole. Patients were followed up for a mean of 15 months with a low relapse rate being apparent in those patients in whom pramipexole was maintained (Fawcett et al. 2016).

Clearly such findings need to be confirmed by double-blind controlled trials. It may be possible to find clinical or neuropsychological markers, which will identify patients likely to respond to pramipexole since it would be predicted that pramipexole would particularly target symptoms such as anhedonia and low motivation. An important clinical point is that the case series used rather higher doses of pramipexole than those reported in clinical trials. It may be therefore that adequate dosing of pramipexole is important in securing a positive clinical benefit. Finally, the case series excluded patients with any evidence of psychotic symptoms at baseline; this seems prudent in view of the known ability of pro-dopaminergic agents to induce psychosis in vulnerable individuals.

Most psychiatrists will not be familiar with the use of pramipexole in clinical practice. It is therefore important to be aware of common adverse effects such as nausea and sleepiness in the early stages of treatment, as well as the possibility of rare, but serious problems, such as sudden sleep attacks, impulse control disorders, compulsive behaviours and dyskinesias.

\section{Anti-inflammatory agents}

Depression is associated with increased blood markers of peripheral inflammation, for example, C-reactive protein (CRP), interleukin-6 (IL-6) and tumour necrosis factor-alpha (TNF- $\alpha$ ) (Raison \& MIller, 2011). There is also preliminary evidence of central inflammation in depression as judged by the increased cortical and subcortical binding in vivo of a specific PET (positron emission tomography) ligand to the translocator protein, a marker of microglial activation (Setiawan et al. 2015). These phenomena show association rather than causation, but it is well recognised that treatment with inflammatory cytokines such as interferon, produces symptoms of major depression in a substantial proportion of patients (Udina et al. 2012). The mechanism of this effect has been intensively studied and may involve changes in glial function and glutamate release (Taylor et al. 2014). It is also possible that inflammation induced activation of the tryptophan metabolising enzyme, IDO (indoleamine 2,3-dioxygenase), would have the effect of lowering tryptophan availability for serotonin synthesis and also producing neurotoxic metabolites such as quinolinic acid (Wichers et al. 2005).

From the point of view of resistant depression, it is of interest that patients with higher levels of inflammation tend to do less well with conventional antidepressant treatment (Carvalho et al. 2013). Interestingly, Uher et al. (2014) found that patients with low levels of CRP showed a better response to escitalopram than to the TCA, nortriptyline; however, the converse was the case when CRP levels were 2 $\mathrm{mg} / \mathrm{l}$ or greater. If this finding is reproducible it might be of significant clinical use in that a simple and widely available blood test such as CRP could serve as a baseline predictor, indicating which patients would do better with noradrenergic rather than serotonergic antidepressants as a first-line treatment.

There may also be a role for specific antiinflammatory treatments in patients with resistant depression. For example, the TNF- $\alpha$ antagonist, infliximab, was found to be effective in patients with resistant depression who had high baseline levels of CRP (Raison et al. 2013). This however was a post hoc analysis and prospective studies are needed to see whether this relationship can be replicated. There is also a meta-analysis suggesting benefit of the COX-2 inhibitor, celecoxib, as an adjunct to the first-line treatment of major depression with either serotonergic or noradrenergic antidepressants (Na et al. 2014).

In a larger meta-analysis of several different antiinflammatory agents (14 randomised trials with over 6000 participants), Köhler et al. (2014) reported that overall, anti-inflammatory treatment was associated with significant improvement in depressive symptoms, though much of the benefit was accounted for by the celecoxib studies. The authors caution that their meta-analysis showed much evidence of heterogeneity together with the possibility of treatment bias. Moreover, observational studies suggested that nonselective NSAIDS might be associated with worse treatment outcome in depression, though confounding by indication was a possible factor for this finding. Anti-inflammatory treatments did not seem to increase gastrointestinal and cardiovascular adverse effects.

\section{Conclusion}

Patients with TRD in the UK are often not well served by the current configuration of psychiatric services, tending to fall in the gap between primary care and specialist services. This review has focused on pharmacological treatment, but this is not to say in any way that psychological treatments are unimportant in resistant depression - quite the contrary. In primary care, there is good evidence that CBT is effective in the treatment of resistant depression (Wiles et al. 2013) and patients with more refractory depression can be helped by long-term psychodynamic therapy, with gains continuing to accrue after the end of treatment (Fonagy et al. 2015). Psychological treatment 
can be particularly important in relapse prevention, which is a major problem in TRD, even when a good clinical remission has been obtained and medication continued (Cowen \& Anderson, 2015). The main problem in instituting specialised psychological treatment is lack of availability. In addition, there continues to be a role for electroconvulsive therapy and perhaps other stimulatory treatments, in the management of resistant depression (see Cowen \& Anderson, 2015).

From the point of view of pharmacological treatment, there is now sufficient high-quality evidence to allow effective sequencing of therapies, starting with simple changes such as antidepressant switching and moving on to evidence-based augmentation strategies. This means that pharmacological treatment in depression should be organised around a rational plan where failure to respond prompts an active change in treatment. Basing clinical prescribing decisions on regular measurement of symptoms and side-effects with standardised rating scales can improve outcome (Guo et al. 2015).

The best-established augmentation treatment is now the addition of low-dose atypical antipsychotic drug treatment, with quetiapine and aripiprazole having the best evidence base. The fact that these two treatments have contrasting adverse event profiles means that an attempt should be made to match patients to the agent they are most likely to tolerate. Other older augmentation treatments such as lithium and T3 also worth considering, and it would be a pity if the often effective combination of lithium and MAOIs were to be lost from clinical practice (Cowen, 2005).

For the future, the development of ketamine as an antidepressant has stimulated much clinical interest and research development and it seems likely that glutamatergic treatments for depression will become available over the next few years, either more easily administered forms of ketamine or other agents hopefully free of dissociative effects and the other potential dangers of ketamine treatment. Whether these new treatments will target NMDA receptors or other glutamatergic mechanisms remains open.

The identification of patients with evidence of concomitant inflammation offers a great opportunity to stratify patients to a treatment that might target a key aspect of pathophysiology. The exciting developments in drug therapies acting on the immune system for other medical conditions offers great opportunities for therapeutic repurposing provided such drugs can be used safely in psychiatric disorders. Finally, the development of pramipexole as an antidepressant is intriguing and if the recently reported benefits can be confirmed, dopamine receptor agonism may offer significant benefit to those treatment-refractory patients who fair poorly with current approaches.

\section{Acknowledgements}

The author is an MRC Clinical Scientist whose work is funded by MRC grant MR/K022202/1.

\section{Declaration of interest}

In the last 3 years P.J.C. has been a paid advisor to Lundbeck.

\section{References}

Barbee JG, Jamhour NJ (2002). Lamotrigine as an augmentation agent in treatment-resistant depression. Journal of Clinical Psychiatry 63, 737-741.

Bauer M, Pfennig A, Linden M, Smolka MN, Neu P, Adli M (2009). Efficacy of an algorithm-guided treatment compared with treatment as usual: a randomized, controlled study of inpatients with depression. Journal of Clinical Psychopharmacology 29, 327-333.

Bedson E, Bell D, Carr D, Carter B, Hughes D, Jorgensen A, Lewis H, Lloyd K, McCaddon A, Moat S, Pink J (2014). Folate Augmentation of Treatment-Evaluation for Depression (FolATED): randomised trial and economic evaluation. Health and Technology Assessments 18, 1-159.

Blanco G, Peters HA (1983). Myeloneuropathy and macrocytosis associated with nitrous oxide abuse. Archives of Neurology 40, 416-418.

Carhart-Harris RL, Bolstridge M, Rucker J, Day CM, Erritzoe D, Kaelen M, Bloomfield M, Rickard JA, Forbes B, Feilding A, Taylor D (2016). Psilocybin with psychological support for treatment-resistant depression: an open-label feasibility study. Lancet Psychiatry 3, 619-627.

Carvalho LA, Torre JP, Papadopoulos AS, Poon L, Juruena MF, Markopoulou K, Cleare AJ, Pariante CM (2013). Lack of clinical therapeutic benefit of antidepressants is associated overall activation of the inflammatory system. Journal of Affective Disorders 148, 136-140.

Cipriani A, Hawton K, Stockton S, Geddes JR (2013). Lithium in the prevention of suicide in mood disorders: updated systematic review and meta-analysis. British Medical Journal 346, f3646.

Collingridge GL, Lee Y, Bortolotto ZA, Kang H, Lodge D (in press). Antidepressant actions of ketamine versus hydroxynorketamine. Biological Psychiatry. http://dx.doi. org/10.1016/j.biopsych.2016.06.029.

Cowen PJ (2005). New drugs, old problems. Advances in Psychiatric Treatment 11, 19-27.

Cowen PJ, Anderson IM (2015). New approaches to treating resistant depression. BJPsych Advances 21, 315-323.

Cusin C, Iovieno N, Iosifescu DV, Nierenberg AA, Fava M, Rush AJ, Perlis RH (2013). A randomized, double-blind, placebo-controlled trial of pramipexole augmentation in treatment-resistant major depressive disorder. Journal of Clinical Psychiatry 74, 636-641.

Dunlop BW, Nemeroff CB (2007). The role of dopamine in the pathophysiology of depression. Archives of General Psychiatry 64, 327-337. 
Fawcett J, Rush AJ, Vukelich J, Diaz SH, Dunklee L, Romo P, Yarns BC, Escalona R (2016). Clinical experience with high-dosage pramipexole in patients with treatment-resistant depressive episodes in unipolar and bipolar depression. American Journal of Psychiatry 173, 107-111.

Fonagy P, Rost F, Carlyle JA, McPherson S, Thomas R, Pasco Fearon RM, Goldberg D, Taylor D (2015). Pragmatic randomized controlled trial of long-term psychoanalytic psychotherapy for treatment-resistant depression: the Tavistock Adult Depression Study (TADS). World Psychiatry 14, 312-321.

Franco-Chaves JA, Mateus CF, Luckenbaugh DA, Martinez PE, Mallinger AG, Zarate CA (2013). Combining a dopamine agonist and selective serotonin reuptake inhibitor for the treatment of depression: a double-blind, randomized pilot study. Journal of Affective Disorders 149, 319-325.

Goldberg JF, Burdick KE, Endick CJ (2004). Preliminary randomized, double-blind, placebo-controlled trial of pramipexole added to mood stabilizers for treatment-resistant bipolar depression. American Journal of Psychiatry 161, 564-566.

Goss AJ, Kaser M, Costafreda SG, Sahakian BJ, Fu CH (2013). Modafinil augmentation therapy in unipolar and bipolar depression: a systematic review and meta-analysis of randomized controlled trials. Journal of Clinical Psychiatry 74, 1101-1107.

Guo T, Xiang YT, Xiao L, Hu CQ, Chiu HF, Ungvari GS, Correll CU, Lai KY, Feng L, Geng Y, Feng Y (2015). Measurement-based care versus standard care for major depression: a randomized controlled trial with blind raters. American Journal of Psychiatry 172, 1004-1013.

Jevtović-Todorović V, Todorovć SM, Mennerick S, Powell S, Dikranian K, Benshoff N, Zorumski CF, Olney JW (1998). Nitrous oxide (laughing gas) is an NMDA antagonist, neuroprotectant and neurotoxin. Nature Medicine 4, 460-463.

Kishimoto T, Chawla JM, Hagi K, Zarate CA, Kane JM, Bauer M, Correll CU (2016). Single-dose infusion ketamine and non-ketamine $N$-methyl-D-aspartate receptor antagonists for unipolar and bipolar depression: a meta-analysis of efficacy, safety and time trajectories. Psychological Medicine 46, 1459-1472.

Köhler O, Benros ME, Nordentoft M, Farkouh ME, Iyengar RL, Mors O, Krogh J (2014). Effect of anti-inflammatory treatment on depression, depressive symptoms, and adverse effects: a systematic review and meta-analysis of randomized clinical trials. JAMA Psychiatry 71, 1381-1391.

Lewis G (2016). Further research needed for severe and chronic depression in specialist mental health services. Lancet Psychiatry 3, 792-793.

Mahableshwarkar AR, Zajecka J, Jacobson W, Chen Y, Keefe RS (2015). A randomized, placebo-controlled, active-reference, double-blind, flexible-dose study of the efficacy of vortioxetine on cognitive function in major depressive disorder. Neuropsychopharmacology 40, 2025-2037.

Mathew SJ, Murrough JW, aan het Rot M, Collins KA, Reich DL, Charney DS (2010). Riluzole for relapse prevention following intravenous ketamine in treatment-resistant depression: a pilot randomized, placebo-controlled continuation trial. International Journal of

Neuropsychopharmacology 13, 71-82.

McAllister-Williams RH, Anderson IM, Finkelmeyer A, Gallagher P, Grunze HC, Haddad PM, Hughes T, Lloyd AJ, Mamasoula C, McColl E, Pearce S (2016).

Antidepressant augmentation with metyrapone for treatment-resistant depression (the ADD study): a double-blind, randomised, placebo-controlled trial. Lancet Psychiatry 3, 117-127.

Montgomery SA, Nielsen RZ, Poulsen LH, Häggström L (2014). A randomised, double-blind study in adults with major depressive disorder with an inadequate response to a single course of selective serotonin reuptake inhibitor or serotonin-noradrenaline reuptake inhibitor treatment switched to vortioxetine or agomelatine. Human Psychopharmacology: Clinical and Experimental 29, 470-482.

Morris R, Garland A, Nixon N, Guo B, James M, Kaylor-Hughes C, Moore R, Ramana R, Sampson C, Sweeney T, Dalgleish T (2016). Efficacy and cost-effectiveness of a specialist depression service versus usual specialist mental health care to manage persistent depression: a randomised controlled trial. Lancet Psychiatry 3, 821-831.

Na KS, Lee KJ, Lee JS, Cho YS, Jung HY (2014). Efficacy of adjunctive celecoxib treatment for patients with major depressive disorder: a meta-analysis. Progress in Neuro-Psychopharmacology and Biological Psychiatry 48, 79-85.

Nagele P, Duma A, Kopec M, Gebara MA, Parsoei A, Walker M, Janski A, Panagopoulos VN, Cristancho P, Miller JP, Zorumski CF (2015). Nitrous oxide for treatment-resistant major depression: a proof-of-concept trial. Biological Psychiatry 78, 10-18.

National Institute for Health and Care Excellence (2009). Depression: The Treatment and Management of Depression in Adults (NICE Clinical Guideline 90). NICE.

Nelson JC, Baumann P, Delucchi K, Joffe R, Katona C (2014). A systematic review and meta-analysis of lithium augmentation in tricyclic and second generation antidepressants in major depression. Journal of Affective Disorders 156, 269-275.

Nelson JC, Papakostas GI (2009). Atypical antipsychotic augmentation in major depressive disorder: a meta-analysis of placebo-controlled randomized trials. American Journal of Psychiatry 166, 980-991.

Nemets B, Stahl Z, Belmaker RH (2002). Addition of omega-3 fatty acid to maintenance medication treatment for recurrent unipolar depressive disorder. American Journal of Psychiatry 159, 477-479.

Nierenberg AA, Fava M, Trivedi MH, Wisniewski SR, Thase ME, McGrath PJ, Alpert JE, Warden D, Luther JF, Niederehe G, Lebowitz B (2006). A comparison of lithium and $\mathrm{T} 3$ augmentation following two failed medication treatments for depression: a STAR* D report. American Journal of Psychiatry 163, 1519-1530.

Nolen WA, Van de Putte JJ, Dijken WA, Kamp JS (1985). L-5HTP in depression resistant to re-uptake inhibitors. An open comparative study with tranylcypromine. British Journal of Psychiatry 147, 16-22. 
Olney JW, Newcomer JW, Farber NB (1999). NMDA receptor hypofunction model of schizophrenia. Journal of Psychiatric Research 33, 523-533.

Pae CU, Wang SM, Han C, Lee SJ, Patkar AA, Masand PS (2015). Quetiapine augmentation for depression: dosing pattern in routine practice. International Clinical Psychopharmacology 30, 54-58.

Papakostas GI, Fava M, Thase ME (2008). Treatment of SSRI-resistant depression: a meta-analysis comparing within-versus across-class switches. Biological Psychiatry 63, 699-704.

Papakostas GI, Ionescu DF (2015). Towards new mechanisms: an update on therapeutics for treatment-resistant major depressive disorder. Molecular Psychiatry 20, 1142-1150.

Papakostas GI, Mischoulon D, Shyu I, Alpert JE, Fava M (2010). S-adenosyl methionine (SAMe) augmentation of serotonin reuptake inhibitors for antidepressant nonresponders with major depressive disorder: a double-blind, randomized clinical trial. American Journal of Psychiatry 167, 942-948.

Papakostas GI, Shelton RC, Zajecka JM, Etemad B, Rickels K, Clain A, Baer L, Dalton ED, Sacco GR, Schoenfeld D, Pencina M (2012). L-methylfolate as adjunctive therapy for SSRI-resistant major depression: results of two randomized, double-blind, parallel-sequential trials. American Journal of Psychiatry 169, 1267-1274.

Paykel ES (2006). Depression: major problem for public health. Epidemiologia e Psichiatria Sociale 15, 4-10.

Pérez V, Gilaberte I, Faries D, Alvarez E, Artigas F (1997). Randomised, double-blind, placebo-controlled trial of pindolol in combination with fluoxetine antidepressant treatment. Lancet 349, 1594-1597.

Pratt LA, Brody DJ (2014). Depression in the U.S. household population, 2009-2012. NCHS Data Brief 172, 1-8.

Raison CL, Miller AH (2011). Is depression an inflammatory disorder? Current Psychiatry Reports 13, 467-475.

Raison CL, Rutherford RE, Woolwine BJ, Shuo C, Schettler P, Drake DF, Haroon E, Miller AH (2013). A randomized controlled trial of the tumor necrosis factor antagonist infliximab for treatment-resistant depression: the role of baseline inflammatory biomarkers. JAMA Psychiatry 70, 31-41.

Rush AJ, Trivedi MH, Wisniewski SR, Nierenberg AA, Stewart JW, Warden D, Niederehe G, Thase ME, Lavori PW, Lebowitz BD, McGrath PJ (2006). Acute and longer-term outcomes in depressed outpatients requiring one or several treatment steps: a STAR* D report. American Journal of Psychiatry 163, 1905-1917.

Setiawan E, Wilson AA, Mizrahi R, Rusjan PM, Miler L, Rajkowska G, Suridjan I, Kennedy JL, Rekkas PV, Houle S, Meyer JH (2015). Role of translocator protein density, a marker of neuroinflammation, in the brain during major depressive episodes. JAMA Psychiatry 72, 268-275.

Simon GE, Khandker RK, Ichikawa L, Operskalski BH (2006). Recovery from depression predicts lower health services costs. Journal of Clinical Psychiatry, 67, 1226-1231.
Spielmans GI, Berman MI, Linardatos E, Rosenlicht NZ, Perry A, Tsai AC (2013). Adjunctive atypical antipsychotic treatment for major depressive disorder: a meta-analysis of depression, quality of life, and safety outcomes. PLoS Medicine 10, e1001403.

Taylor MJ, Godlewska B, Near J, Christmas D, Potokar J, Collier J, Klenerman P, Barnes E, Cowen PJ (2014). Effect of interferon- $\alpha$ on cortical glutamate in patients with hepatitis C: a proton magnetic resonance spectroscopy study. Psychological Medicine 44, 789-795.

Trivedi MH, Fava M, Wisniewski SR, Thase ME, Quitkin F, Warden D, Ritz L, Nierenberg AA, Lebowitz BD, Biggs MM, Luther JF (2006). Medication augmentation after the failure of SSRIs for depression. New England Journal of Medicine 354, 1243-1252.

Udina M, Castellví P, Moreno-España J, Navinés R, Valdés M, Forns X, Langohr K, Solà R, Vieta E, Martín-Santos R (2012). Interferon-induced depression in chronic hepatitis $C$ : a systematic review and meta-analysis. Journal of Clinical Psychiatry 73, 1128-1138.

Uher R, Tansey KE, Dew T, Maier W, Mors O, Hauser J, Dernovsek MZ, Henigsberg N, Souery D, Farmer A, Peter $\mathbf{M}$ (2014). An inflammatory biomarker as a differential predictor of outcome of depression treatment with escitalopram and nortriptyline. American Journal of Psychiatry 171, 1278-1286.

Wichers MC, Koek GH, Robaeys G, Verkerk R, Scharpe S, Maes M (2005). IDO and interferon- $\alpha$-induced depressive symptoms: a shift in hypothesis from tryptophan depletion to neurotoxicity. Molecular Psychiatry 10, 538-544.

Wiles N, Thomas L, Abel A, Ridgway N, Turner N, Campbell J, Garland A, Hollinghurst S, Jerrom B, Kessler D, Kuyken W (2013). Cognitive behavioural therapy as an adjunct to pharmacotherapy for primary care based patients with treatment resistant depression: results of the CoBalT randomised controlled trial. Lancet 381, 375-384.

Wilkinson ST, Sanacora G (2016). Ketamine: a potential rapid-acting anti-suicidal agent? Depression and Anxiety 33, 711-717.

Zanos P, Moaddel R, Morris PJ, Georgiou P, Fischell J, Elmer GI, Alkondon M, Yuan P, Pribut HJ, Singh NS, Dossou KS, Fang Y, Huang X-P, Mayo CL, Wainer IW, Albuquerque EX, Thompson SM, Thomas CJ, Zarate CA, Gould TD (2016). NMDAR inhibition-independent antidepressant actions of ketamine metabolites. Nature 533, 481-486.

Zarate CA, Payne JL, Singh J, Quiroz JA, Luckenbaugh DA, Denicoff KD, Charney DS, Manji HK (2004). Pramipexole for bipolar II depression: a placebo-controlled proof of concept study. Biological Psychiatry 56, 54-60.

Zhou X, Ravindran AV, Qin B, Del Giovane C, Li Q, Bauer M, Liu Y, Fang Y, da Silva T, Zhang Y (2015). Comparative efficacy, acceptability, and tolerability of augmentation agents in treatment-resistant depression: systematic review and network meta-analysis. Journal of Clinical Psychiatry 76, $487-498$. 